\title{
A Survey of the Occurrence of Fusarium Mycotoxins in Biscuits in Japan by Using LC/MS
}

\author{
Hiroki Tanaka, ${ }^{*}, a, 1$ Yoshiko Sugita-Konishi, ${ }^{a}$ Masahiko Takino, ${ }^{b}$ Toshitsugu Tanaka, ${ }^{c}$ \\ Akira Toriba, ${ }^{d}$ and Kazuichi Hayakawa ${ }^{d}$
}

${ }^{a}$ National Institute of Health Sciences, 1-18-1 Kamiyoga, Setagaya-ku, Tokyo 158-8501, Japan, ${ }^{b}$ Agilent Technologies Japan, Limited, Hachioji Site, 9-1 Takakura-cho, Hachioji-shi, Tokyo 192-8501, Japan, ${ }^{c}$ Kobe Institute of Health, 4-6 Minatojima-Nakamachi, Chuoku, Kobe 650-0046, Japan, and ${ }^{d}$ Institute of Medical, Pharmaceutical and Health Sciences, Kanazawa University, Kakuma-machi, Kanazawa 920-1192, Japan

(Received January 4, 2010; Accepted January 18, 2010; Published online January 22, 2010)

By adopting a rapid and sensitive method for simultaneous detection of nivalenol (NIV), deoxynivalenol (DON), fusarenon-X (FX), 3-acetyl deoxinivalenol (3ADON), HT-2 toxin (HT-2), T-2 toxin (T-2) and zearalenone (ZEN), the natural occurrence of these mycotoxins in biscuits made of wheat (201 samples) in Japan was surveyed. Samples were analyzed by LC/MS with atmospheric pressure photo ionization (APPI). Further confirmation was performed by liquid chromatography/time of flight mass spectrometry (LC/TOFMS). The average contamination of each Fusarium mycotoxin was 3.1, 23, 0.7, 0.1 and $4.2 \mathrm{ng} / \mathrm{g}$ for NIV, DON, HT-2, T-2 and ZEN, respectively. Multiple toxins were observed in 120 samples while FX and 3ADON were not detected. The incidence of these toxins was $41 \%$ for NIV, $98 \%$ for DON, $19 \%$ for HT-2, $11 \%$ for T-2 and $2 \%$ for ZEN. There were no significant differences in the concentration and incidence between conventional biscuits made of wheat and biscuits made of wheat for infants. This is the first report concerning the presence of NIV, DON, HT-2, T-2 and ZEN in biscuits in Japan.

Key words — Fusarium mycotoxin, contamination survey, LC/MS, LC/time of flight mass spectrometry, biscuit, Japan

\section{IINTRODUCTION}

Trichothecene mycotoxins (TRs), such as nivalenol (NIV), deoxynivalenol (DON), fusarenon$\mathrm{X}(\mathrm{FX}), 3$-acetyl deoxynivalenol (3ADON), HT-2 toxin (HT-2) and T-2 toxin (T-2), belong to the secondary toxic metabolites produced by various filamentous fungi, such as Fusarium graminearum, $F$. culmorum and $F$. sporotrichioides.

TRs exhibit a potent inhibitory activity toward protein and DNA syntheses in eukaryotic cells, and this biological activity is closely related to their high lethality to animals, cellular damage to actively

\footnotetext{
${ }^{1}$ Present address: Research Center, Suntory Business Expert Limited, 1-1-1 Wakayamadai, Shimamoto-cho, Mishima-gun, Osaka 618-8503, Japan

*To whom correspondence should be addressed: National Institute of Health Sciences, 1-18-1 Kamiyoga, Setagaya-ku, Tokyo 158-8501, Japan. Tel.: +81-3-3700-1141; Fax: +813-3700-9527; E-mail: hiroki.t@ poem.ocn.ne.jp
}

dividing cells, potent suppression of immunoresponses $^{1,2)}$ and inhibition of protein synthesis. ${ }^{3,4)}$

Zearalenone (ZEN) is an estrogenic metabolite produced by Fusarium species such as $F$. graminearum, F. culmorum and F. crookwellense (F. cerealis), and causes hyperestrogenism in livestock. ${ }^{5,6)}$

Co-contamination of Fusarium mycotoxins (TRs and ZEN) occurs worldwide in agricultural commodities and consumption of these has caused several outbreaks of intoxication in human and animal populations. ${ }^{7-12}$ ) With the development of highly sensitive and simultaneous analytical methods, many reports regarding the co-contamination of Fusarium mycotoxins in processed cereal foods have been reported in Europe and North America, ${ }^{13-15)}$ but relatively little work is available for Asian countries despite these depending heavily on imported wheat and wheat-derived products. Thus, an accurate determination of processed food contaminated with these toxins is an urgent need for 
food supply.

The purpose of this study was to simultaneously determine of TRs and ZEN based on a method established in a previous study. ${ }^{16)}$ Furthermore, by using this method, we determined the incidence and concentration of Fusarium mycotoxins in biscuits made of wheat in Japan for the first time and to use this information to evaluate the potential health risk to Japanese consumers.

\section{MATERIALS AND METHODS}

Samples — A total of 201 samples of biscuits made of wheat were purchased from random local retail shops throughout Japan between the summer 2004 and summer 2006, including 110 of infant food, 39 imported, 17 domestic and the remaining of unknown origin. All samples were stored at $4^{\circ} \mathrm{C}$ until analysis.

Chemicals and Reagents — The standards for NIV, DON, FX, 3ADON, HT-2, T-2 and ZEN were obtained from Sigma-Aldrich Japan (Tokyo, Japan). HPLC grade acetonitrile, HPLC grade methanol and reagent grade ammonium acetate were obtained from Wako Chemical (Osaka, Japan). Water was purified with a Milli-Q system (Millipore, Tokyo, Japan). MultiSep \#226 columns (Romer Labs, Inc., Union, MO, U.S.A.) were purchased from Showa Denko Limited (Tokyo, Japan). All other reagents were of the highest analytical grade available.

LC/MS — The LC/MS was performed using a Shimadzu Model LC-2010C $C_{H T}$ liquid chromatograph system (Shimadzu, Kyoto, Japan) including a degassing unit, a binary gradient pump, an autoinjector, a column oven and a Shimadzu LCMS2010A mass spectrometer with atmospheric pressure photo ionization (APPI) capabilities. Liquid chromatography (LC) separation was performed on a $150 \mathrm{~mm} \times 2.0 \mathrm{~mm}$ inside diameter (I.D.) column packed with a $5 \mu \mathrm{m}$ Shimadzu Shim-pack VP-ODS. The LC mobile phase was a mixture of aqueous $10 \mathrm{mM}$ ammonium acetate (A) and methanol (B). The initial gradient condition was $90 \% \mathrm{~A}$ and $10 \%$ $\mathrm{B}$, and was equilibrated for $5 \mathrm{~min}$. Then, solvent B was changed linearly to $100 \%$ in $20 \mathrm{~min}$, and was held for $10 \mathrm{~min}$. The flow rate was set at $0.1 \mathrm{ml} / \mathrm{min}$. Further, acetone was added after the diode array detector at a flow rate of $60 \mu \mathrm{l} / \mathrm{min}$ via a tee by an isocratic pump (Agilent Technologies, Waldbronn, Germany). The column temperature was maintained at $40^{\circ} \mathrm{C}$ and the injection volume was $10 \mu \mathrm{l}$. MS experiments were performed in the APPI mode. Nitrogen as the nebulizer gas in the ion source was generated from pressurized air by a SLP-07-S2 (ANEST IWATA Co., Yokohama, Japan). The following analytical conditions for APPI were optimized by using an analytical column with the mixture standard of 7 Fusarium mycotoxins at $100 \mathrm{ng} / \mathrm{ml}$. The probe voltage, probe temperature, nebulizer gas, drying gas, curved desolvation line $(\mathrm{CDL})$ voltage, CDL temperature, block heater temperature, Q-array direct current (DC) and Q-array radio frequency (RF) were set at $0 \mathrm{~V}, 200^{\circ} \mathrm{C}, 2.5 \mathrm{l} / \mathrm{min}, 0 \mathrm{MPa}, 5 \mathrm{~V}, 150^{\circ} \mathrm{C}, 150^{\circ} \mathrm{C}$, $5 \mathrm{~V}$ and $150 \mathrm{~V}$, respectively. Acetone was used as the dopant solvent. The quantitative analysis of each Fusarium mycotoxin was carried out using the selected ion monitoring (SIM) mode of each base ion peak at $m / z 371$ (NIV), 355 (DON), 413 (FX), 397 (3ADON), 483 (HT-2) and 317 (ZEN) in the negative mode and $m / z 484$ (T-2) in the positive mode, respectively (Table 1 ).

LC/Time of Flight Mass Spectrometry (TOFMS) — The LC/TOFMS instrument and condition for analysis of Fusarium mycotoxins were reported in an earlier paper. ${ }^{17)}$

Table 1. SIM for the Analysis of Target Analytes

\begin{tabular}{|c|c|c|c|c|c|c|c|}
\hline \multirow[t]{2}{*}{ Mycotoxins } & \multirow[t]{2}{*}{ M.W. ${ }^{a)}$} & \multicolumn{6}{|c|}{ Ionization mode } \\
\hline & & & APPI & & APCI & & ESI \\
\hline NIV & 312 & 371 & {$\left[\mathrm{M}+\mathrm{CH}_{3} \mathrm{COO}^{-}\right.$} & 371 & {$\left[\mathrm{M}+\mathrm{CH}_{3} \mathrm{COO}\right]^{-}$} & 371 & {$\left[\mathrm{M}+\mathrm{CH}_{3} \mathrm{COO}\right]^{-}$} \\
\hline DON & 296 & 355 & {$\left[\mathrm{M}+\mathrm{CH}_{3} \mathrm{COO}\right]^{-}$} & 355 & {$\left[\mathrm{M}+\mathrm{CH}_{3} \mathrm{COO}\right]^{-}$} & 355 & {$\left[\mathrm{M}+\mathrm{CH}_{3} \mathrm{COO}\right]^{-}$} \\
\hline FX & 354 & 413 & {$\left[\mathrm{M}+\mathrm{CH}_{3} \mathrm{COO}\right]^{-}$} & 413 & {$\left[\mathrm{M}+\mathrm{CH}_{3} \mathrm{COO}\right]^{-}$} & 413 & {$\left[\mathrm{M}+\mathrm{CH}_{3} \mathrm{COO}\right]^{-}$} \\
\hline $3 \mathrm{ADON}$ & 338 & 397 & {$\left[\mathrm{M}+\mathrm{CH}_{3} \mathrm{COO}^{-}\right.$} & 339 & {$[\mathrm{M}+\mathrm{H}]^{+}$} & 397 & {$\left[\mathrm{M}+\mathrm{CH}_{3} \mathrm{COO}\right]^{-}$} \\
\hline HT-2 & 424 & 483 & {$\left[\mathrm{M}+\mathrm{CH}_{3} \mathrm{COO}\right]^{-}$} & 483 & {$\left[\mathrm{M}+\mathrm{CH}_{3} \mathrm{COO}\right]^{-}$} & 483 & {$\left[\mathrm{M}+\mathrm{CH}_{3} \mathrm{COO}\right]^{-}$} \\
\hline $\mathrm{T}-2$ & 466 & 484 & {$\left[\mathrm{M}+\mathrm{NH}_{4}\right]^{+}$} & 484 & {$\left[\mathrm{M}+\mathrm{NH}_{4}\right]^{+}$} & 484 & {$\left[\mathrm{M}+\mathrm{NH}_{4}\right]^{+}$} \\
\hline ZEN & 318 & 317 & {$[\mathrm{M}]^{-}$} & 317 & {$[\mathrm{M}]^{-}$} & 317 & {$[\mathrm{M}]^{-}$} \\
\hline
\end{tabular}

a) M.W. ; Molecular weight. 
Preparation of Standard Solution and Samples — The mixture of TRs and ZEN standard solutions $(10 \mu \mathrm{g} / \mathrm{ml})$ for stock and fortification experiments were dissolved in acetonitrile and stored at $4^{\circ} \mathrm{C}$ in the dark until use. For preparation of a mixed working standard solution, an appropriate amount of individual stock standard solution was evaporated to dryness at $40^{\circ} \mathrm{C}$ under a gentle stream of nitrogen. The residue was dissolved in $1 \mathrm{ml}$ of aqueous $10 \mathrm{mM}$ ammonium acetate/methanol (90/10). For fortification experiments, $50 \mu \mathrm{l}$ of the stock standard solution was spiked into $10 \mathrm{~g}$ of blank samples $(=50 \mathrm{ng} / \mathrm{g})$ before extraction. Three replicates for each level were prepared.

Sample extraction and cleanup was carried out as follows. Ten grams of each sample was weighed in a $100 \mathrm{ml}$ Erlenmeyer flask, suspended in $40 \mathrm{ml}$ acetonitrile/water (85/15) and shaken for $30 \mathrm{~min}$. The mixed solution was centrifuged for $5 \mathrm{~min}$ at $1410 \mathrm{~g}$, and then $10 \mathrm{ml}$ of the supernatant were applied to a MultiSep \#226 cartridge column for the cleanup. After discarding the first $3 \mathrm{ml}$ of elutant, the next $2 \mathrm{ml}$ were collected and evaporated to dryness at $40^{\circ} \mathrm{C}$ under a gentle stream of nitrogen. The residue was dissolved in $1.0 \mathrm{ml}$ of aqueous $10 \mathrm{mM}$ ammonium acetate/methanol (90/10).

The analysis of TRs and ZEN was carried out using primary screening with LC/MS, and confirmed with LC/TOFMS.

\section{RESULTS AND DISCUSSION}

\section{Comparison of Ionization Techniques for LC/MS Analysis}

Ionization methods were compared: APPI, electrospray ionization (ESI) and atmospheric chemical ionization (APCI) modes. The SIM of each Fusarium mycotoxin was evaluated in the scan mode $(\mathrm{m} / \mathrm{z}$ 100-500) by direct injection of each Fusarium mycotoxin standard $(1 \mu \mathrm{g} / \mathrm{ml})$ without the use of an analytical column. The most sensitive ion differed depending on the mycotoxin, ionization, polarity, and ammonium adduct ion $\left(\left[\mathrm{M}+\mathrm{NH}_{4}\right]^{+}\right)$and acetic acid adduct ion $\left(\left[\mathrm{M}+\mathrm{CH}_{3} \mathrm{COO}\right]^{-}\right)$(Table 1). In order to achieve maximum sensitivity, the instrument detection limits (IDLs) were calculated when the peak to peak signal-to-noise $(\mathrm{S} / \mathrm{N})$ ratio was 3 by injecting $10 \mu \mathrm{l}$ of a mixture standard solution of TRs and ZEN. As shown in Table 2, the APPI mode provided the optimum intensity for NIV, DON and ZEN. Although the ESI mode showed the strongest intensity
Table 2. Instrument Detection Limits of Fusarium Mycotoxins by LC/MS

\begin{tabular}{lccc}
\hline \hline Mycotoxins & \multicolumn{3}{c}{ Instrument detection limits ${ }^{a)}(\mathrm{pg})$} \\
\cline { 2 - 4 } & APPI & APCI & ESI \\
\hline NIV & 1.8 & 2.5 & 2.4 \\
DON & 2.5 & 4.5 & 8.5 \\
FX & 7.7 & 6.3 & 7.7 \\
3ADON & 2.1 & 8.3 & 1.0 \\
HT-2 & 6.8 & 5.0 & 14 \\
T-2 & 4.3 & 6.8 & 6.5 \\
ZEN & 1.3 & 4.3 & 1.7 \\
\hline
\end{tabular}

a) Instrument detection limits defined as $\mathrm{S} / \mathrm{N}$ ratio $=3$. Injection volume of the standard solution was $10 \mu \mathrm{l}$.

of $3 \mathrm{ADON}$, the effect of a sample matrix is possibly high. ${ }^{16)}$ A recent report describes the optimization of NIV and DON detection using the APPI mode; ${ }^{16)}$ therefore, we used the APPI mode to analyze the 7 Fusarium mycotoxins in this study.

Matrix effects are a major problem for mycotoxin quantification by LC/MS. The sample matrix may either enhance or suppress the ionization of mycotoxins; however, the effects vary from sample to sample ultimately affecting the quantitative performance of the LC/MS system. To evaluate matrix effects, the concentration of 7 Fusarium mycotoxins ranging from 1 to $500 \mathrm{ng} / \mathrm{ml}$ in solvent standard and spiked biscuit samples were analyzed. The calibration curves for both conditions showed good linearity with correlation coefficients $\left(r^{2}\right)$ above 0.999 . However, the slope of the linearity curve for ZEN in the spiked biscuit matrix standard was about $89 \%$ lower than the solvent standard (data not shown). These results indicate that ZEN showed a matrix effect of ion suppression.

To evaluate recoveries, the proposed method was applied to the analysis of biscuit samples spiked with known concentrations of Fusarium mycotoxins. Samples were spiked at a final concentration of 50 ng/g for all 7 Fusarium mycotoxins. Quantification was carried out by the solvent standard and biscuit matrix matched standard. The mean recovery of each Fusarium mycotoxin in spiked samples ranged from 28 to $121 \%$ in the solvent standard and from 83 to $120 \%$ in the matrix matched standard (Table 3 ). At the same concentration, the experiment was repeatable $(n=3)$ with relative standard deviations (RSDs) ranging from 3.4 to $13 \%$ in solvent standard and from 1.0 to $11 \%$ in matrix matched standard (Table 3). Under these conditions, ZEN showed a large matrix effect on ion suppression, because $\mathrm{ZEN}$ is different structure to have the macrolide ring 
Table 3. Recoveries, Limits of Detection and Limits of Quantification of Fusarium Mycotoxins in Spiked Biscuits by LC/MS

\begin{tabular}{|c|c|c|c|c|c|}
\hline Mycotoxins & Standard & $\begin{array}{c}\text { Recovery }^{a)} \\
(\%)\end{array}$ & $\begin{array}{c}\mathrm{RSD}^{a)} \\
(\%)\end{array}$ & $\begin{array}{c}\begin{array}{c}\text { Limit } \text { of detection } \\
(\mathrm{ng} / \mathrm{g})\end{array} \\
\end{array}$ & $\begin{array}{c}\begin{array}{c}\text { Limit of quantification }^{b)} \\
(\mathrm{ng} / \mathrm{g})\end{array} \\
\end{array}$ \\
\hline NIV & $\begin{array}{l}\text { Solvent } \\
\text { Matrix }\end{array}$ & $\begin{array}{l}94 \\
83\end{array}$ & $\begin{array}{l}3.4 \\
3.8\end{array}$ & 1.4 & 4.7 \\
\hline DON & $\begin{array}{l}\text { Solvent } \\
\text { Matrix }\end{array}$ & $\begin{array}{l}105 \\
104\end{array}$ & $\begin{array}{l}6.1 \\
1.0\end{array}$ & 0.9 & 3.0 \\
\hline FX & $\begin{array}{l}\text { Solvent } \\
\text { Matrix }\end{array}$ & $\begin{array}{l}121 \\
120\end{array}$ & $\begin{array}{l}6.2 \\
4.2\end{array}$ & 1.2 & 4.1 \\
\hline $3 \mathrm{ADON}$ & $\begin{array}{l}\text { Solvent } \\
\text { Matrix }\end{array}$ & $\begin{array}{l}116 \\
112\end{array}$ & $\begin{array}{l}4.8 \\
4.9\end{array}$ & 1.3 & 4.2 \\
\hline HT-2 & $\begin{array}{l}\text { Solvent } \\
\text { Matrix }\end{array}$ & $\begin{array}{l}115 \\
115\end{array}$ & $\begin{array}{l}11 \\
11\end{array}$ & 0.6 & 2.0 \\
\hline $\mathrm{T}-2$ & $\begin{array}{l}\text { Solvent } \\
\text { Matrix }\end{array}$ & $\begin{array}{l}116 \\
113\end{array}$ & $\begin{array}{l}9.2 \\
8.9\end{array}$ & 0.1 & 0.3 \\
\hline ZEN & $\begin{array}{l}\text { Solvent } \\
\text { Matrix }\end{array}$ & $\begin{array}{l}28 \\
97\end{array}$ & $\begin{array}{l}13 \\
5.4\end{array}$ & 4.2 & 14 \\
\hline
\end{tabular}

a) Recoveries and RSDs were calculated on the basis of three replicates at $50 \mathrm{ng} / \mathrm{g}$. $b$ ) Limits of detection and limits of quantification calculated by the biscuit matrix matched standard defined as $\mathrm{S} / \mathrm{N}$ ratio $=3$ and 10 , respectively.

Table 4. Occurrence of Fusarium Mycotoxins in Biscuits

\begin{tabular}{lccc}
\hline \hline Mycotoxins & $\begin{array}{c}\text { Positive samples } \\
(\text { Incidence, } \%)\end{array}$ & $\begin{array}{c}\text { Range } \\
(\mathrm{ng} / \mathrm{g})\end{array}$ & $\begin{array}{c}\text { Mean }^{b)} \\
(\mathrm{ng} / \mathrm{g})\end{array}$ \\
\hline NIV & $83(41)$ & $1.4-35$ & 3.1 \\
DON & $196(98)$ & $0.9-791$ & 23 \\
HT-2 & $38(19)$ & $0.6-20$ & 0.7 \\
T-2 & $22(11)$ & $0.1-6.0$ & 0.1 \\
ZEN & $4(2)$ & $4.2-4.4$ & 4.2 \\
\hline
\end{tabular}

a) Number of samples analyzed $=201 . b$ ) When the number of samples of under the limit of quantification is $>60 \%$, the concentration was calculated as follows. The value less than the limit of detection was calculated as the detection limit. The value between the limit of detection and the limit of quantification was calculated as the limit of quantification. When the number of samples of under the limit of quantification is $<60 \%$, the concentration was calculated as follows. The value under the limit of quantification was calculated as $1 / 2$ of the limit of detection.

and is a low polar compound when compared with the six other TRs, and is thus considered susceptible to matrix effects; therefore, the biscuit matrix matched standard was used for the quantitation of all 7 Fusarium mycotoxins throughout this study.

The limits of detection (LODs) and limits of quantification (LOQs) of the TRs and ZEN in biscuits were determined by the signal corresponding to three times and ten times the background noise on each SIM chromatogram, respectively. The LODs and LOQs of each Fusarium mycotoxin ranged from 0.1 to $4.2 \mathrm{ng} / \mathrm{g}$ and from 0.3 to $14 \mathrm{ng} / \mathrm{g}$, respectively (Table 3 ).

\section{Analysis of TRs and ZEN in Biscuits Based on Wheat}

The developed method was applied in the quantitation of Fusarium mycotoxins in biscuits made of wheat. The level of occurrence of Fusarium myco- toxins in biscuits is represented in Table 4 and typical chromatograms of standard mixture and extracts from naturally contaminated biscuit shown in Fig. 1. Fusarium mycotoxins were quantified in 196 out of the 201 samples with DON being the most commonly detected Fusarium mycotoxin in this study. It was found in $98 \%$ of all samples at concentrations between 0.9 and $791 \mathrm{ng} / \mathrm{g}$ (mean $=23 \mathrm{ng} / \mathrm{g}$ ). In this study, 120 samples were co-contaminated with two or more Fusarium mycotoxins. With the exception of two samples (NIV/HT-2 and HT-2/T-2), all samples with multiple toxins also contained DON. The co-contamination of two or more toxins detected in this study were found in 120 (incidence $=60 \%$ ) samples. In samples containing two toxins, DON was present in combination with each of NIV, HT-2 and ZEN, and both NIV and DON occurred as the most frequent combination in 77 (incidence $=38 \%$ ) samples. Of these, 99, 16, and 5 
Table 5. Occurrence of Fusarium Mycotoxins in Biscuits for Infants

\begin{tabular}{lccc}
\hline \hline Mycotoxins & $\begin{array}{c}\text { Positive samples }^{a)} \\
(\text { Incidence, } \%)\end{array}$ & $\begin{array}{c}\text { Range } \\
(\mathrm{ng} / \mathrm{g})\end{array}$ & $\begin{array}{c}\text { Mean }^{b)} \\
(\mathrm{ng} / \mathrm{g})\end{array}$ \\
\hline NIV & $37(34)$ & $1.4-35$ & 3.0 \\
DON & $98(89)$ & $0.9-177$ & 17 \\
HT-2 & $25(23)$ & $0.6-11$ & 1.4 \\
T-2 & $13(12)$ & $0.1-6.0$ & 0.4 \\
ZEN & $1(1)$ & 4.2 & - \\
\hline
\end{tabular}

a) Number of samples analyzed $=110 . b$ ) When the number of samples of under the limit of quantification is $>60 \%$, the concentration was calculated as follows. The value less than the limit of detection was calculated as the detection limit. The value between the limit of detection and the limit of quantification was calculated as the limit of quantification. When the number of samples of under the limit of quantification is $<60 \%$, the concentration was calculated as follows. The value under the limit of quantification was calculated as $1 / 2$ of the limit of detection.
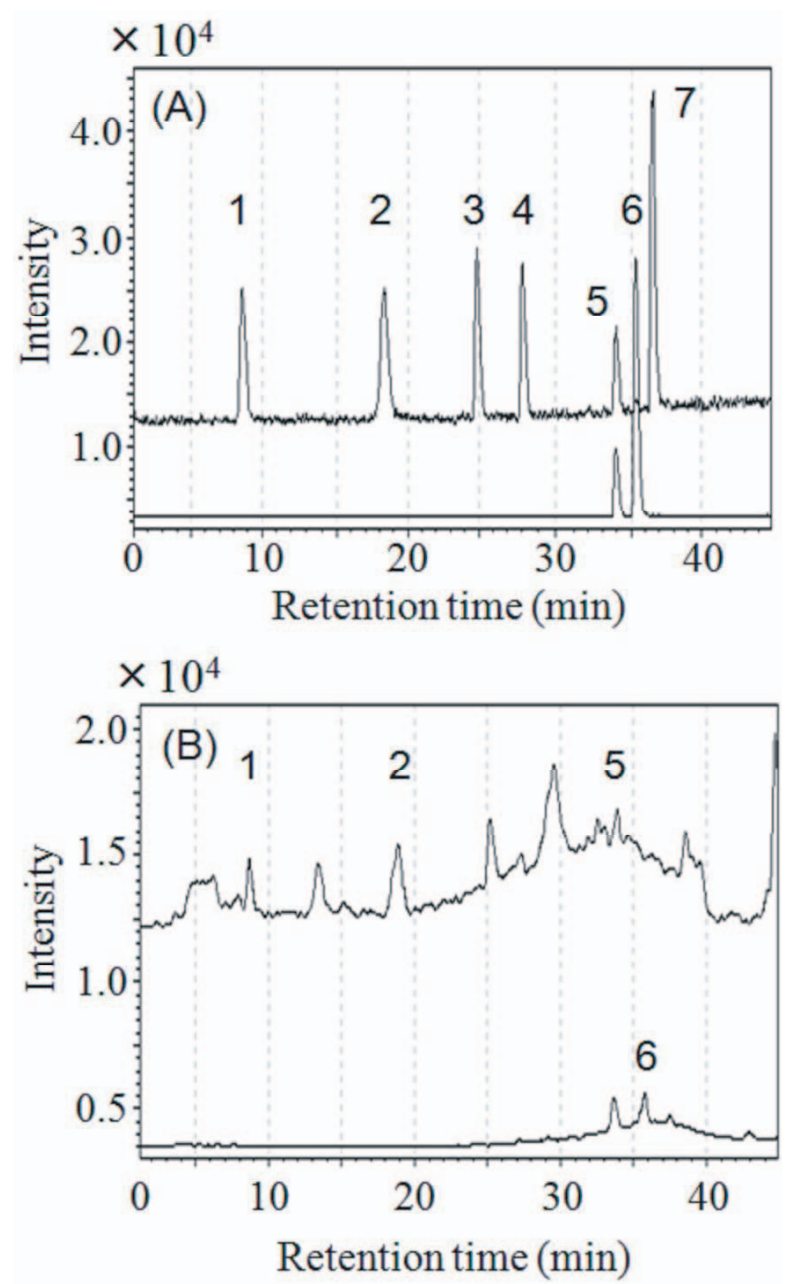

Fig. 1. Total Ion Chromatograms of (A) Fusarium Mycotoxins Standard Mixture Solution at $50 \mathrm{ng} / \mathrm{ml}$ and (B) Naturally Contaminated Biscuit

(A) 1, NIV; 2, DON; 3, FX; 4, 3ADON; 5, HT-2; 6, T-2; 7, ZEN. (B) 1 , NIV (13 ng/g); 2, DON (22 ng/g); 5, HT-2 (4 ng/g); 6, $\mathrm{T}-2(1 \mathrm{ng} / \mathrm{g})$.

samples contained 2, 3, and 4 toxins, respectively. Triple toxin combinations were DON/HT-2/T-2 and NIV/DON/ZEN while a combination of four toxins was NIV/DON/HT-2/T-2 (Fig. 1). In infant bis- cuits the concentration of DON ranged from 0.9 to $177 \mathrm{ng} / \mathrm{g}($ mean $=17 \mathrm{ng} / \mathrm{g}$, Table 5).

NIV was found in $41 \%$ of the samples, ranging from 1.4 to $35 \mathrm{ng} / \mathrm{g}$ (mean = $3.1 \mathrm{ng} / \mathrm{g}$, Table 4$)$.

HT-2 and T-2 were detected in 38 (incidence $=19 \%$ ) and 22 (incidence $=11 \%$ ) samples, with a maximum concentration of $20 \mathrm{ng} / \mathrm{g}$ (mean = $0.7 \mathrm{ng} / \mathrm{g}$ ) and $6.0 \mathrm{ng} / \mathrm{g}$ (mean $=0.1 \mathrm{ng} / \mathrm{g}$ ), respectively (Table 4). Both HT-2 and T-2 were observed in infant products and occurred simultaneously in one sample. Since the simultaneous occurrence of HT- 2 and T-2 is rare in Japan, we recommend continuation of this surveillance monitoring program.

The incidence $(2 \%)$ and highest concentration $(4.4 \mathrm{ng} / \mathrm{g})$ of ZEN in the samples were lower than those of the other six Fusarium mycotoxins (Table 4).

In contrast, none of the samples analyzed were found to contain FX and 3ADON above the LODs.

Biselli and Hummert reported the co-occurrence of DON and T-2 in wheat-based products in Europe. ${ }^{13)}$ They showed that DON contamination was high (maximum level $=2350 \mathrm{ng} / \mathrm{g}$ ), but the concentration of T-2 was lower than that in our study (maximum level $=0.95 \mathrm{ng} / \mathrm{g}$ ). Schollenberger et al. $^{18)}$ showed that NIV, DON, HT-2, T-2 and ZEN occurred in foodstuffs marketed in Germany with DON the most commonly observed. The incidence of HT-2 was higher than that of T-2, differences depending on the kind of sample, similarly to the incidence of NIV and ZEN. These results were similar to our present study. Recently, there have been some reports in which NIV, DON, HT-2 and ZEN were detected in infant products and conventional wheat products. ${ }^{14,15,19,20)}$ Compared with these reports the maximum DON and HT-2 concentrations were similar to our study of infant products. Although the occurrence of NIV and ZEN was confirmed in these reports, that of T-2 was not, and on 
this point it was different from our study of infant products.

As shown in Tables 4 and 5, there were no great differences in the incidence and concentration between conventional biscuits and biscuits for infants. However, the risk will be greater for infants due to body weight and intake when compared to adults.

It is difficult to assess the exposure of Fusarium mycotoxins under the present study because the general information data regarding real consumption of biscuits by Japanese is limited. Therefore, continuous surveillance for contamination levels and an exposure assessment will be required to avoid an unexpected risk of exposure to high concentrations of mycotoxins from now on.

In conclusion, we are the first to report the presence of NIV, DON, HT-2, T-2 and ZEN in biscuits marketed in Japan. It is suggested from our study that biscuits are co-contaminated with several Fusarium mycotoxins; therefore, there is a need for continuous monitoring in order to evaluate their risk to consumers. In addition, it should be taken into account that the risk of Fusarium mycotoxins may be increased by co-occurrence with other mycotoxins, as shown in this study. It is important to continue accumulating the occurrence data of mycotoxins from food products in order to develop appropriate risk assessment tools with the goal of reducing contamination levels in marketed commodities.

\section{REFERENCES}

1) Ueno, Y. (1980) Trichothecene mycotoxins: mycology, chemistry and toxicology. In Advances in Nutritional Research, Vol.3 (Draper, H. H., Ed.), Plenum, New York, pp.301-353.

2) Ueno, Y. (1983) General toxicology. In Trichothecenes: Chemical, Biological and Toxicological Aspects (Ueno, Y., Ed.), Elsevier, Amsterdam, pp.135146.

3) Shifrin, V. I. and Anderson, P. (1999) Trichothecene mycotoxins trigger a ribotoxic stress response that activates c-Jun $\mathrm{N}$-terminal kinase and p38 mitogenactivated protein kinase and induces apoptosis. $J$. Biol. Chem., 274, 13985-13992.

4) Yang, G. H., Jarvis, B. B., Chung, Y. J. and Pestka, J. J. (2000) Apoptosis induction by the satratoxins and other trichothecene mycotoxins: relationship to ERK, p38 MAPK, and SAPK/JNK activation. Toxicol. Appl. Pharmacol., 164, 149-160.

5) Miller, J. D. and Trenholm, H. L. (Eds.) (1994)
Mycotoxins in Grain-Compounds Other Than Aflatoxin, Eagan Press, St. Paul.

6) Mirocha, C. J., Pathre, S. V. and Christensen, M. (1977) In Mycotoxins in Human and Animal Health (Rodricks, J. V., Hesseltine, C. W. and Mehlman, M. A., Eds.), Pathotox, IL, p.345.

7) World Health Organization (WHO) (1990) Selected Mycotoxins: Ochratoxins, Trichothecens, Ergot. Environmental Health Criteria 105, WHO, Geneva.

8) Müller, H.-M., Reimann, J., Schumacher, U. and Schwadorf, K. (1998) Natural occurrence of Fusarium toxins in oats harvested during five years in an area of southwest Germany. Food Addit. Contam., 15, 801-806.

9) Tanaka, T., Hasegawa, A., Yamamoto, S., Lee, U.-S., Sugiura, Y. and Ueno, Y. (1988) Worldwide contamination of cereals by the Fusarium mycotoxins nivalenol, deoxynivalenol, and zearalenone. 1. Survey of 19 countries. J. Agric. Food Chem., 36, 979-983.

10) Tanaka, T., Yamamoto, S., Hasegawa, A., Aoki, N., Besling, J. R., Sugiura, Y. and Ueno, Y. (1990) Asurvey of the natural occurrence of Fusarium mycotoxins, deoxynivalenol, nivalenol and zearalenone, in cereals harvested in the Netherlands. Mycopathologia, 110, 19-22.

11) Yoshizawa, T. (1991) In Mycotoxins and Animal Foods (Smith, J. E. and Henderson, R. S., Eds.), CRC Press, Boca Raton, FL, p. 301.

12) Yuwai, K. E., Rao, K. S., Singh, K., Tanaka, T. and Ueno, Y. (1994) Occurrence of nivalenol, deoxynivalenol, and zearalenone in imported cereals in Papua, New Guinea. Nat. Toxins, 2, 19-21.

13) Biselli, S. and Hummert, C. (2005) Development of a multicomponent method for Fusarium toxins using LC-MS/MS and its application during a survey for the content of T-2 toxin and deoxynivalenol in various feed and food samples. Food Addit. Contam., 22, 752-760.

14) Lombaert, G. A., Pellaers, P., Roscoe, V., Mankotia, M., Neil, R. and Scott, P. M. (2003) Mycotoxins in infant cereals foods from the Canadian retail market. Food Addit. Contam., 20, 494-504.

15) Schollenberger, M., Suchy, S., Jara, H. T., Drochner, W. and Muller, H.-M. (1999) A survey of Fusarium toxins in cereal-based foods marketed in an area of southwest Germany. Mycopathologia, 147, 49-57.

16) Tanaka, H., Takino, M., Sugita-Konishi, Y., Tanaka, T., Toriba, A. and Hayakawa, K. (2009) Determination of nivalenol and deoxynivalenol by liquid chromatography/atmospheric pressure photo ionizationmass spectrometry. Rapid Commun. Mass Spectrom., 23, 3119-3124. 
17) Tanaka, H., Takino, M., Sugita-Konishi, Y. and Tanaka, T. (2006) Development of a liquid chromatography/time-of-flight mass spectrometric method for the simultaneous determination of trichothecenes, zearalenone and aflatoxins in foodstuffs. Rapid Commun. Mass Spectrom., 20, 14221428.

18) Schollenberger, M., Müller, H.-M., Rüfle, M., Suchy, S., Planck, S. and Drochner, W. (2005) Survey of Fusarium toxins in foodstuffs of plant origin marketed in Germany. Int. J. Food Microbiol., 97,
317-326.

19) Cirillo, T., Ritieni, A., Galvano, F. and AmodioCocchieri, R. (2003) Natural co-occurrence of deoxynivalenol and fumonisins B1 and B2 in Italian marketed foodstuffs. Food Addit. Contam., 20, 566571.

20) Food Standards Agency (2003) Survey of Retail Cereal Products for Trichothecenes and Zearalenone. Food Survey Information Sheet, No.35/03, http:// www.food.gov.uk/multimedia/pdfs/35cereal.pdf 